\title{
OS POSTULADOS DO LIBERALISMO E A CRISE DO PODER DE PUNIR DO ESTADO
}

Cristina S. Alves Lourenço

Doutora em Direito Penal e Criminologia. Membro do Conselho de Política Criminal e Penitenciária do Estado do Pará - Brasil. Diretora do Departamento de Direito Criminal da Escola Superior da Advocacia. Professora de Direito Penal e Criminologia da Graduação e Pós-Graduação do Centro Universitário do Pará CESUPA e Faculdade Estácio - FAP. Advogada.

\section{Resumo}

O Liberalismo introduziu uma nova forma de pensar e de sentir o homem. Este deveria ser titular de direitos e por isso não poderia estar mais à mercê de um poder arbitrário e desumano que empregava perseguiçóes religiosas e restriçóes. Com a introdução desses novos postulados que hoje são imprescindíveis à convivência em sociedade e também ao desenvolvimento do homem como ser de direitos. No entanto, ao revés do que aconteceu no chamado Estado Liberal, em que o cidadão se preocupava com as suas garantias frente ao Estado intervencionista, porque se via como um objeto, hoje, o cidadão também se preocupa com suas garantias, mas baseado em outro fundamento, agora não se vê como um objeto, mas sim como vítima, passando a requerer um aumento da segurança. Do mesmo modo, a criação dos novos riscos, inerente a uma civilização que se quer avançada em termos tecnológicos, tende a não mais limitar o poder punitivo do Estado diante de uma efetiva lesão grave de um bem jurídico importante e carente de tutela penal; com isso, o Estado tende a aumentar seu poder repressivo, infligindo muitas vezes princípios básicos de um Estado que se quer garantidor, formando-se um paradoxo. De um lado, cidadáos querendo segurança e abrindo mão cada vez mais de sua liberdade e, do outro, o Estado "garantidor", cerceando cada vez mais as liberdades, ultrapassando os limites impostos pelos vários princípios e gerando uma grande insegurança jurídica. Com a problemática posta, o presente estudo adotou o método dedutivo no qual foi possível observar que: (i) a utilização de leis penais em branco, sem um parâmetro a ser seguido, infringem o Princípio da Legalidade; (ii) a inclusão desenfreada de leis que, inúmeras vezes possuem conteúdo vago e impreciso, violam o Princípio da Legalidade e da Intervenção Mínima; (iii) a proliferação dos delitos de perigo (abstrato e concreto), elevando-se os atos preparatórios à delitos, causando, assim, uma violação ao Princípio da Intervenção Mínima; (iv) uma mudança no conceito de bem jurídico, que cede aos interesses individuais em prol dos interesses coletivos, buscando uma nova fundamentação; 
(v) diante dessas alteraçóes, a pena tende a ser mais elevada e fator de exclusão, mas nem por isso mais eficaz e o Direito Penal tende a descer o gráfico da pirâmide e converter-se em prima ratio da sociedade.

\section{Palavras-chave}

Liberalismo; Poder Punitivo do Estado; Princípio da Legalidade.

\section{Abstract}

The liberalism introduced a new way of thinking and feeling man. This should be the right holder and so could not be more at the mercy of an arbitrary and inhuman power which employed religious persecution and restrictions. With the introduction of these new postulates that today are essential to living together in society and the development of man as a being of rights. However, the reverse of what happened in the so called Liberal State, where citizens worried about their front guarantees to the interventionist state, because they saw it as an object; Today, the citizen is also concerned with their guarantees, but based on other grounds, not now sees itself as an object, but as a victim going to require an increase in security. Similarly, the creation of new risks inherent in a civilization that wants advanced in technological terms, tends to no longer limit the punitive power of the state before an actual serious injury of an important legal interest and lacking in criminal custody, with therefore, the state tends to increase their repressive power inflicting often basic principles of a state that wants guarantor. Forming a paradox, on the one hand citizens wanting security giving up more and more of their freedom, and on the other the state "guarantor" abridging increasingly freedoms, surpassing the limits imposed by the various principles and generating a great legal uncertainty. To put problems, this study adopted the deductive method in which it was observed that: (i) the use of criminal laws blank, without a parameter to follow, violating the Principle of Legality; (ii) the inclusion of rampant laws many times have vague and imprecise content, violating the Principle of Legality and Minimum Intervention; (iii) the proliferation of dangerous offenses (abstract and concrete), rising acts preparatory to the offenses, thus causing a breach of the Minimum Intervention Principle; (iv) a change in the legal and concept that gives the individual interests in favor of collective interests, seeking a new foundation; (v) the face of these changes, the penalty tends to be higher and exclusion factor but no more effective and criminal law, tends to lower the graphic of the pyramid and turn into material ratio of society.

\section{Key words}

Liberalism; Punitive Power of the State; Principle of Legality. 


\section{A Evolução do Estado}

O Estado é a sociedade política organizada, que apresenta povo, território e poder, tendo por características gerais a complexidade de organização e atuação; a institucionalização do poder nos órgáos representativos; a capacidade de exercer coerçáo (em âmbito penal, por exemplo); a autonomia do exercício do poder político; e a sedentariedade, no que se refere à "continuidade não só no tempo, mas também no espaço, no duplo sentido de ligaçáo do poder e da comunidade a um território e de necessária fi-

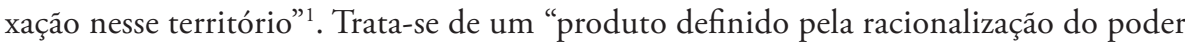
que objetiva atender aos anseios de segurança, certeza e previsibilidade exigidos pelas emergentes sociedades de massa" ${ }^{2}$.

Para a manutenção da ordem em uma sociedade faz-se necessária a utilização da coerção estatal, porém o uso dessa força, sem moderação e sem a devida necessidade, torna seu uso ilegítimo, mesmo que na repressão de um ilícito, podendo o Estado passar facilmente de agente garantidor a agente repressor, transformando a sua finalidade, que é assegurar a tranquila convivência em sociedade.

Desde a Idade Média, culminando na Revolução Francesa, se requer que o uso do poder punitivo deve respeitar as pessoas e suas liberdades, ensejando, por consequência, a minimização do poder do Estado perante os cidadãos, devendo o governo dos homens se transformar em governo das leis ou da razão ${ }^{3}$.

O Estado Liberal, emanado do Iluminismo, tem como pressupostos: o império da lei orientada à defesa dos direitos (que eram anteriores e transcendiam o próprio Estado) e liberdades fundamentais, a separação de poderes e a legalidade da atividade administrativa.

Em sentido liberal, cuida-se:

De la relación que el Estado mantiene com el derecho, relación que, trasel triunfo del movimiento constitucional, solo podía consistir em la plena sumisión del Estado a la norma júridica. Se entiende así que el núcleo fundamental de La categoría Estado de Derecho lo constituyera la idea de imperio de laley $[\ldots]^{4}$.

1 MIRANDA, Jorge. Teoria do estado e da constituição. $3^{\text {a }}$ ed. Rio de Janeiro: Forense, 2011, p. 6.

2 MORAIS, José Luis Bolzan de; NASCIMENTO, Valéria Ribas do. Constitucionalismo e cidadania: por uma jurisdição constitucional democrática. Porto Alegre: Livraria do Advogado, 2010, p. 40.

3 Isso se tornaria uma faca de dois gumes, já que a ideia de que só o que está na lei correspondia ao direito permitiu a fundamentação de Estados Totalitários que se resguardavam sob o manto da legalidade.

4 MORALES, Ángel Garrorena. Teoría de laconstitución y sistema de fuentes. Madrid: Centro de Estudios Políticos y Constitucionales, 2011, p. 51-52. 
Diante disso, almeja-se garantir que não haja intromissão do Estado nas relaçóes entre indivíduos e essa intromissão somente será permitida para assegurar a coexistência das liberdades individuais por meio do Direito.

É nesse sentido o entendimento de Zagrebelsky ao afirmar que o Estado de Direito indica um valor e aponta uma direção de desenvolvimento do corpo estatal. Como valor, a eliminação da arbitrariedade do seio da máquina pública por meio de um controle legal das atividades dos detentores do poder político. Quanto à direção, seria a inversão da relação entre poder e direito: não mais rex facit legem e sim lex facit regem ${ }^{5}$.

Cabe ressaltar que no Estado de Direito (liberal) a classe dominante (burguesia) "formulou os princípios filosóficos de sua revolta social" e depois "nada mais fez do que generalizá-los doutrinariamente como ideais comuns a todos os componentes do corpo social". Porém, "no momento em que se apodera do controle político da sociedade, a burguesia já não se interessa em manter na prática a universalidade daqueles princípios, como apanágio de todos os homens", os quais foram sustentados somente de modo formal, "uma vez que no plano de aplicação política eles se conservam, de fato, princípios constitutivos de uma ideologia de classe"6.

Na Primeira Grande Guerra, o Estado passa de liberal a social, havendo então a inclusão dos direitos sociais nos textos constitucionais. $\mathrm{O}$ marco inicial foi a Constituição do México de 1917 e atingiu a Europa em 1919 com a Constituição de Weimar, que era entendida como um texto de natureza formal que dispunha acerca do que o Estado (ente político) poderia ou não fazer, não havendo, porém, relação vinculante, o que na prática resultou na não observância, por parte do poder público, dos direitos sociais nela contidos, transformando-se em exemplo de texto constitucional ineficaz ${ }^{7}$.

Com a Segunda Guerra Mundial, passa-se a dar maior importância aos princípios como forma de oposição à doutrina do império da lei.

Em razão da crise de governabilidade gerada pelo Estado Social passa-se à criação de um Estado Constitucional regido pela supremacia da Constituiçáo e, por vezes, referido

5 "El Estado de derecho indica un valor y alude sólo a una de las direcciones de desarrollo de la organización del Estado, pero no encierra en sí consecuencias precisas. El valor es la eliminación de la arbitrariedad en el ámbito de la actividad estatal que afecta a los ciudadanos. La dirección es la inversión entre la relación entre poder y derecho que constituía la quintaesencia del machstaat y del polizeistaat: no más rex facit legem, sino lex facit regem" (ZAGREBELSKY, Gustavo. El derecho dúctil: ley, derechos y justicia. 10. ed. Madrid: Trotta, 2011, p. 21).

6 BONAVIDES, Paulo. Do estado liberal ao estado social. 11. ed. São Paulo: Malheiros, 2013, p. 42.

7 "O problema principal dos direitos fundamentais de Weimar era o de sua força de validez. Na literatura bramia há um litígio sobre isto, se e em qual proporção as normas de direitos fundamentais, do título de direitos fundamentais, eram meras proposiçōes programáticas sem força vinculativa jurídica” (ALEXY, Robert. Constitucionalismo discursivo. Tradução de Luís Afonso Heck. 3. ed. Porto Alegre: Livraria do Advogado, 2011, p. 98). 
como sinônimo de Estado Democrático de Direito ${ }^{8}$, onde se tem a construção de uma dogmática constitucional emancipatória?.

Silva afirma que o Estado Democrático se refere à "garantia geral dos direitos da pessoa humana" e não somente de uma classe ou de um grupo determinado de pessoas eventualmente no controle político ou não, fazendo-se aplicar a todos os componentes da sociedade e que, para se materializar, "há de ser um processo de convivência social numa sociedade livre, justa e solidária, em que o poder emana do povo e deve ser exercido em proveito do povo, diretamente ou por representantes eleitos" ${ }^{10}$. Nesse contexto, vale referir o art. 2º da Constituição da República Portuguesa de 1986, segundo o qual o Estado Democrático de Direito é:

Baseado na soberania popular, no pluralismo de expressão e organização política democrática, no respeito e na garantia de efetivação dos direitos e liberdades fundamentais e na separação e interdependência de poderes, visando à realização da democracia econômica, social e cultural e o aprofundamento da democracia participativa.

A ampliação ilimitada dos horizontes do Direito Penal para que solucione problemas que outras áreas jurídicas (ou não) não resolvem e dá margem a uma distorção na própria caracterização desse ramo como ciência. A importância do tipo penal e seu significado na estruturação da proteção da sociedade se encontram desgastados.

Dessa maneira, o Direito Penal é chamado para resolver todos os problemas que afligem a sociedade, como meio de pacificar a situação e refletir uma ideia de proteção. Esse caráter simbólico que o Direito Penal adquire se perfaz em consequência da ineficácia que possui para resolver esses problemas para o qual foi eleito, já que:

[...] cuanto más amplio sea el campo del Derecho penal, menos se podrá esperar que éste atienda a cuestiones fundamentales; un Derecho penal

8 "O Estado Democrático de Direito tem um conteúdo transformador da realidade, não se restringindo, como o Estado Social de Direito, a uma adaptação melhorada das condiçóes sociais de existência. Assim, o seu conteúdo ultrapassa o aspecto material de concretização de uma vida digna ao homem e passa a agir simbolicamente como fomentador da participação pública no processo de construção e reconstrução de um projeto de sociedade, apropriando-se do caráter incerto da democracia para veicular uma perspectiva de futuro voltada à produção de uma nova sociedade, onde a questão da democracia contém e implica, necessariamente, a solução do problema das condiçóes materiais de existência” (STRECK, Lenio Luiz; MORAIS, Jose Luis Bolzan. Comentário ao art. $1^{\circ}$, caput. In: CANOTILHO, José Joaquim Gomes et al. (Coords.). Comentários à Constituição do Brasil. São Paulo: Saraiva/Almedina, 2013, p. 113-116).

9 "Na moderna concepçáo do direito constitucional desenvolveu-se uma renovada linha doutrinária conhecida como dogmática constitucional emancipatória, tendo esta vertente o objetivo de estudar o texto constitucional à luz da ideia de dignidade da pessoa humana" (CLÈVE, Clemerson Merlin. Para uma dogmática constitucional emancipatória. Belo Horizonte: Fórum, 2012, p. 15-16, grifos no original).

10 SILVA, José Afonso da. Curso de direito constitucional positivo. 36. ed. São Paulo: Malheiros, 2013, p. 119-121. 
excesivamente amplio tendrá necesariamente como objeto cuestiones secundarias, al contrario de lo que ocurre com un Derecho penal cuyo núcleo se concentra en intereses vitales de las personas ${ }^{11}$.

É bem verdade que essa função simbólica pode desenvolver-se levando em consideração que os meios de comunicação, com sua capacidade de chegar ao grande público e de influenciar em sua opinião, atendem aos anseios do legislador, que não está preocupado com o bem comum, mas sim com fins pessoais. Diante disso, o Estado tende a aumentar seu poder repressivo, infringindo, muitas vezes, princípios básicos de um Estado que se quer garantidor, formando-se um paradoxo: de um lado, cidadãos querendo segurança, abrindo mão, cada vez mais, de sua liberdade; e do outro, o Estado "garantidor", cerceando, cada vez mais, as liberdades, ultrapassando os limites impostos pelos vários princípios e gerando uma grande insegurança jurídica.

\section{O Direito Penal "Moderno"}

\subsection{Proliferação de Leis Penais em Branco ${ }^{12}$}

A proliferação de leis penais em branco serve ao esfacelamento do Princípio da Legalidade, que obriga o legislador a determinar a conduta proibida, devendo a lei penal ser prévia, escrita, estrita e certa.

Este princípio está intimamente ligado com os ideários do Iluminismo, tratando de proteger ao cidadão contra o poder de punir ilimitado. Isso ocorre a partir do momento em que há necessidade de serem elencadas, mediante normas, as condutas que não podem ser praticadas e as que devem ser praticadas, surgindo assim a possibilidade de o cidadão conhecer o que pode ou não fazer, assim como surge para o Estado a fundamentação para a possível punição. O que deve ser considerado como crime deve ser elecando de maneira prévia, certa, escrita e estrita. Além disso, é necessário que essa norma tenha tanto vigência quanto validade, ou seja, que tenha seguido os trâmites de elaboração e votação e promulgação exigidos para uma lei ordinária e que tenha conformidade com a Lei Maior.

O princípio fica afetado quando o legislador não estabelece com claridade o suposto de fato, já que sua remissão se fará a uma norma de hierarquia inferior, podendo resultar "riesgos de deslegalización de la materia penal y, en definitiva, de posible ejercicio de competencia legislativa por instancias que no la poseen"13.

11 HASSEMER, Winfried. Por qué y con qué fin se aplican las penas? Revista de Derecho Penal y Criminología, n. 3, p. 317-331, 1999, p. 328.

12 Sobre a utilidade e necessidade de sua utilização ver MUÑOZ, Conde, F.; GARCÍA ARÁN, M. Derecho Penal. Parte General,.Valencia, Ed. Tirant Lo Blanch, 5. ed., 2002, p. 38-39.

13 GARCÍA ARÁN, Mercedes. Remisiones normativas, leyes penales en blanco y estructura de la norma penal. Estudios Penales y Criminológicos, n.16, p. 65-103, 1993, p. 66. 
A possibilidade de remissão enfrenta, em primeiro lugar, o problema da normativa reguladora em matéria penal, pois entendemos que sempre afeta direitos fundamentais. Não podemos esquecer que a norma penal tem função de proteção de bens jurídicos, empregando meios de especial gravidade nos casos de ataques mais ofensivos à convivência da sociedade ${ }^{14}$.

Outra questão se refere a como podemos articular a garantia da irretroatividade da lei penal em relação à sucessão normativa de leis de hierarquia inferior à qual se remetem as leis penais em branco. Nesse sentido, adverte Silva Sànchez que, da mesma maneira que não se pode aplicar retroativamente uma lei desfavorável, não se pode assegurar que uma norma extrapenal posterior, que atenua os efeitos punitivos, deva ser aplicada ao réu ${ }^{15}$.

O único meio de preservar o teor garantista que possui este Princípio é obrigar o legislador a descrever, de maneira mais precisa possível, o núcleo essencial da proibição, ficando, se houver necessidade, à norma de menor hierarquia unicamente os elementos complementários, mas náo essenciais e, dessa maneira, o princípio opera como limite da reserva de lei e como mantenedor da seguridade jurídica.

\subsection{Limite Mínimo e Máximo da Pena como Expressão de uma Finalidade de Prevenção Geral}

Em decorrência das exigências acima citadas, foi necessário estabelecer para cada norma que protegia um bem jurídico, uma pena a ser aplicada. Essa pena abstrata, prevista pelo legislador, deveria ter um mínimo e um máximo que deveria refletir a valoração atribuída ao bem jurídico que estava sendo protegido mediante aquela norma.

Quando a pena passava de um plano abstrato e genérico para um plano concreto e individual, a dosagem deveria levar em consideração a gravidade do delito e as finalidades da sanção a ser aplicada. Em razão disso, o correto seria afirmar que a pena a ser aplicada em razáo da individualizaçáo feita pela sentença deveria primar pela prevenção geral e especial positivas.

Assim, quando houvesse a imposição de uma pena estaria se confirmando o valor daquele bem jurídico e também buscando que aquele condenado não praticasse mais fatos descritos como crimes, procurando a ressocialização do mesmo.

Mas será que a análise ainda pode ser vista assim? Isso porque o estabelecimento do mínimo e máximo para uma pena sempre esteve ligado à questão de legalidade. Era

14 Sobre a função da normativa penal de proteção de bens jurídicos e de motivação, ver GARCÍA ARÁN, M., op. cit., p.57-65; e FIGUEIREDO DIAS, J., Direito Penal 2. Parte Geral: As Consequências Jurídicas do Crime. Coimbra, Faculdade de Direito, 1988, p. 43 e ss.

15 SILVA SÁNCHEZ, Jesus Maria. Legislación penal socio-económica y retroactividad de disposiciones favorables: el caso de las "leyes penales en blanco". Revista Juridica de Cataluña, n.1, p. 87-89, 1994. 
necessário haver parâmetros para o legislador e aplicador da lei. Mas que parâmetros são esses e em que estão fundados?

É notório perceber que o mínimo e o máximo deixaram de ser uma fundamentação apenas legalista passando para um plano funcionalista, ou seja, a aferição de um mínimo e máximo de pena tem ligação direta com a finalidade que se quer com esses limites.

Diante das últimas alteraçóes e criaçóes feitas pelo legislador penal nos parece claro que a finalidade a ser atingida tem sido a prevenção geral negativa, ou seja, intimidar. Isso reflete a política de emergência e a função simbólica do direito penal.

Ora, se o que buscamos através dos limites impostos à pena é uma intimidação geral, quem poderá nos deter? Quanto é necessário para que essa intimidação realmente aconteça? A pena deve primar por isso?

Se a legalidade foi a causa e fim da introdução de limites para a aplicação da pena, hoje essa mesma legalidade foi reduzida a segunda plano, o que interessa é conseguir através de sançóes cada vez mais duras, reprimir a criminalidade crescente, intimidando todos e qualquer um.

\subsection{Ampliação dos Limites do Direito Penal e Consequente Ampliação de Leis Penais}

A ampliação dos horizontes do direito penal, para que solucione problemas que outras áreas jurídicas não resolvem, dá margem a uma distorção na própria caracterização desse ramo como ciência.

O Direito Penal se configura como uma das instâncias de controle social confirmadora das outras instâncias, devendo ser utilizado somente quando estas se revelem insuficientes para a proteção desses bens jurídicos, que possuem relevância constitucional e necessidade de proteção penal e somente quando haja uma grave lesão a esses bens jurídicos; e também quando quem afeta ao bem jurídico deve ser merecedor de pena (Princípio da Lesividade e da Fragmentariedade).

Nesse sentido, o princípio da intervenção mínima se coloca como o centro de tensão entre o Estado Democrático e o Estado Social, já que no Estado Democrático se tem a identificaçáo com o princípio da intervenção mínima tanto em relação à descriminalização quanto com a redução das penas aflitivas; enquanto que no Estado Social se tem a identificação com novas formas de delitos para satisfazer a proteção de interesses coletivos.

O Direito Penal é chamado para resolver todos os problemas que afligem a sociedade, como meio de pacificar a situação e refletir uma ideia de proteção. Esse caráter 
simbólico que o Direito Penal adquire é gerado em consequência da ineficácia que possui para resolver os problemas para os quais foi escolhido, já que:

[...] cuanto más amplio sea el campo del Derecho penal, menos se podrá esperar que éste atienda a cuestiones fundamentales; un Derecho penal excesivamente amplio tendrá necesariamente como objeto cuestiones secundarias, al contrario de lo que ocurre com un Derecho penal cuyo núcleo se concentra en intereses vitales de las personas"16.

Como ensina Hassemer:

El Derecho penal y la pena han sido elevados a la categoría de fuente de expectativas para la solución de los grandes problemas políticos y sociales, y la necesidad perentoria de actuar` se asocia, para los responsables de calmarla, con el aumento de prohibiciones, intervenciones y sanciones penales"17.

Essa manifestação crescente de produçáo de leis, aliadas à percepçáo de que essas leis nascem defeituosas tanto como ao cumprimento das garantias formais como materiais, afeta a um valor intrínseco da vida humana, que é a segurança jurídica ${ }^{18}$. $\mathrm{O}$ indivíduo, a cada dia, enxerga-se mais limitado em seus direitos e em sua liberdade.

O Direito Penal deve se configurar como uma das instâncias de controle social confirmadora das outras instâncias, devendo ser utilizado somente quando estas se revelem insuficientes para o desenvolvimento normal da sociedade.

O Direito Penal deve proteger, essencialmente, os bens jurídicos fundamentais da sociedade e só intervir quando há uma conduta que lesione gravemente esses bens jurídicos. Daí resulta a relevância constitucional e a necessidade de proteção penal dos bens jurídicos; e que a conduta deve ser merecedora de pena ${ }^{19}$.

Assim, o Princípio da Intervenção Mínima se coloca como o centro de tensão entre o Estado Democrático de Direito e o Estado Social porque no Estado Democrático tem-se a identificação com o Princípio da Intervenção Mínima, tanto em relação à descriminalização como com a reduçáo das penas sobre o duplo lema: "menos delitos" y "menos prisão". Já no Estado Social tem-se a identificação com novas formas de delitos para satisfazer a proteção de novos interesses, como os de natureza coletiva.

16 HASSEMER, W. “¿Por qué y con qué fin se aplican las penas?” en Revista de Derecho Penaly Criminología, no 3, 1999, p. 328.

17 HASSEMER, 1999, p. 319.

18 Ver SILVA SÁNCHEZ, Jesus Maria. Nuevas tendencias político-criminales y actividad jurisprudencial del Tribunal Supremo. Actualidade Pena, n.15/8, 1996, p. 250; MUÑOZ CONDE, Francisco. El «Moderno» derecho penal en el nuevo código penal: principios y tendencias. La Ley, n.3, 1996.

19 A respeito da dignidade penal ver ANDRADE, Manuel Costa. A dignidade penal y la carência de tutela penal, como referências de uma doutrina teológico-racional do crime. Coimbra, [s.d.]. 


\subsection{A Questão dos Tipos Penais de Perigo}

A criação de novos tipos penais de perigo se dá como forma de antecipar a barreira protetiva do Estado, em razão das transformaçóes tecnológicas que, ao lado do progresso e do bem-estar, também trouxeram riscos ${ }^{20}$.

Contudo, cabe salientar que não são todos os riscos que são proibidos, há certos riscos que pertencem a uma esfera a qual a sociedade tem que tolerar, por serem necessários e úteis. São os chamados "riscos permitidos".

Disso resultam inúmeros questionamentos, como: em que medida se pode admitir a atividade perigosa em razão do desenvolvimento técnico, científico e do bem-estar social? Qual o nível tolerável para esses riscos? Qual o critério valorativo para estipular se um risco é permitido?

Esses riscos fazem com que o legislador extenda a área de atuação do Direito Penal, fazendo com que a lei antecipe a incriminação à possibilidade de lesão. Prittwitz se refere a esse caráter expansivo do Direito Penal com um significado tridimensional: ampliação da área de proteção a novos bens jurídicos, antecipação à punição e, com isso, a diminuição nas exigências de reprovação ${ }^{21}$.

Essa antecipação se fará por meio de algumas técnicas legislativas, como: os delitos de perigo abstrato ou concreto ${ }^{22}$, a elevação a delitos de atos preparatórios ou de formas de participação e os chamados "delitos de obstáculos"23.

Há, portanto, o abandono do Direito Penal de lesão, próprio do Estado liberal clássico, passando, cada vez mais, a utilizar o Direito penal de perigo, próprio do Estado de prevenção.

Deve-se considerar que, para que haja o menor prejuízo possível aos princípios do Estado Democrático, o legislador deverá atentar para o fato de que tais condutas a serem tipificadas possuem uma probabilidade de lesão, já que o que se deve evitar não é o perigo,

20 Ver SILVA SÁNCHEZ, Jesus Maria. La expansión del derecho penal: aspectos de la política criminal en las sociedades postindustriales. Madrid: Civitas, 1999.

21 PRITTWITZ, Cornellius. Sociedad del riesgo y Derecho Penal. In: Material del Programa de Doctorado "Problemas Actuales del Derecho Penal y de la Criminología". n. 6, 2003.

22 No que tange as dificuldades na legitimaçáo constitucional dos delitos de perigo abstrato, SILVA SÁNCHEZ, entende que estes devem ser considerados, tentativa de delitos de perigo concreto, expressamente tipificados. SILVA SÁNCHEZ, Jesus Maria. Consideraciones dogmáticas y de política legislativa sobre el fenómeno de la conducción suicida. La Ley, n. 3, p. 977 e ss., 1998. Sobre os delitos de perigo abstrato, BARBERO SANTOS, M. Contribución al estudio de los delitos de peligro abstracto. ADPCP, p. 488 e ss., 1973. RODRÍGUEZ MONTAÑES, T. Delitos de peligro, dolo e imprudencia. Madrid, 1994, p. 238-239; TÓRIO LÓPEZ, A. Los delitos de peligro hipotético. ADPCP, T. XLIV, 1991.

23 Termo utilizado por alguns autores, entre eles MANTOVANI, para designar aqueles delitos que castigam atos que se manifestam como possibilidade para a comissão de outros delitos. Por todos, ver MANTOVANI, F. Diritto penale: parte generale. 3. ed. Padova: CEDAM, 1992, p. 236 e ss. 
mas sim a lesão ao bem jurídico. Isso é o que legitima a intervenção penal nos delitos de perigo $^{24}$.

\subsection{Conceito de Bem Jurídico ${ }^{25}$}

Este conceito depende sempre das condiçóes sociais, econômicas e culturais de uma determinada sociedade em um dado momento histórico.

Podemos aceitar que as raízes desse conceito de bem jurídico, que está vinculado ao conceito material de crime, se encontram no período do Iluminismo e vem evoluindo, passando por Birnbaum, Binding, Liszt, Honig e Schwinge, não significando que seja uma linha constante de evolução, mas sim que:

La impresión que la historia del bien jurídico deja es la de un proceso en espiral a lo largo del cual se sucedieron fenómenos de revolución en el sentido etimológico(revolutio), de retorno al que juzgava ya irrepetiblemente abandonado. No menos vincada es la impresión de extrema liquidez y mimetismo del concepto, capaz de asumir los contenidos y desempeñar los papeles aparentemente mas irreconciliables y antinó$\operatorname{micos}^{26}$.

Em sociedades democráticas, o Direito Penal é visto como instrumento de proteção de bens jurídicos e estes operam como limite e fundamento ao direito de punir do Estado.

Esses bens jurídicos, em razão do Estado Democrático, devem ter uma índole social, devem-se proteger os interesses coletivos que afetam a todos os indivíduos ${ }^{27}$, sem se perder de vista que devem ter como fundamento um bem individual ${ }^{28}$ e tenham necessidade de tutela penal para que não se estenda a incidência do Direito Penal, já que este somente deve intervir quando uma conduta possa constituir um obstáculo para o exercício dos direitos dos cidadãos.

24 Contrariando esse posicionamento, o que se proíbe não é o perigo de lesão ou a lesão mesma do bem jurídico, e sim a "perigosidade geral". O risco passaria nesse sentido a ser motivo para o legislador tipificar uma conduta.

25 Sobre os vários conceitos de bens jurídicos ver JESCHECK, H., Tratado de Derecho Penal. - Parte General, Vol. I, Barcelona, Bosch, p. 9-10; ROXIN, C., "Sentido y Limites de la Pena Estadual", en Problemas Básicos del Derecho Penal, Madrid, Reus, 1976, p. 21; MUÑOZ CONDE, F.; GARCÍA ARÁN, M., Derecho Penal. Parte General., Valencia, Ed. Tirant Lo Blanch, 5a edición, 2002, p. 59; POLAINO NAVARRETE, M., El Bien Jurídico en el Derecho Penal, Universidade de Sevilla, 1974, p. 356.

26 COSTA ANDRADE, M., "A Nova Lei dos Crimes contra a Economia à Luz do Conceito de 'Bem Jurídico"”, in Direito Penal Económico, Coimbra, Centro de Estudos Judiciários, 1985, p. 76.

27 CARBONELL, J.C., "Breves reflexiones sobre la tutela de los llamados intereses difusos", en CDJ, XXXVI, 1994, Monografía "Intereses difusos y Derecho Penal”, p. 11 y ss.

28 No sentido de que todos os bens jurídicos supra-individuais possuem uma referência individual, ibídem, p. 16 e ss. 


\subsection{Os Fins da Pena}

Os fins da pena é algo difícil de diagnosticar, já que, frente ao fracasso da ideia de ressocialização e de uma expansiva ideia de insegurança, vemo-nos novamente diante da ideia de retribuição, que há muito deixou de ter interesse no Direito Penal, uma vez que esta teoria entendia a pena como um fim em si mesmo, sem uma finalidade.

$\mathrm{Na}$ atualidade, há uma conjugação de finalidades porque se reconhece que esta deve ter uma finalidade, ao menos de prevenção general.

\subsubsection{Retribuição}

Não há como negar que essa finalidade está presente sempre que se comina ou se aplica uma pena. A nossa sociedade, apesar de ter evoluído e passado por tantas Revoluçôes, em que se pregava a humanização, o respeito ao outro, a igualdade, a liberdade, não conseguiu se desvencilhar da ideia de vingança e consequentemente de aplicação de pena privativa de liberdade.

Para contribuir ainda mais, temos o fracasso da ideia de ressocializaçao e de uma expansiva ideia de insegurança que nos traz mais uma vez à Teoria da Retribuição.

A pena é a expiação dos pecados, é o acalento para a sociedade. O que vemos são Códigos Penais cada vez mais repressivos, reduzindo o âmbito de aplicação das penas alternativas com a consequente ampliação da pena de prisão.

\subsubsection{Prevenção Geral}

Em sua vertente negativa, a pena é uma mensagem à sociedade, com o fim de proteger bens jurídicos. Pode derivar de uma ideia de ameaça e causar um terror penal.

Essa ideia de mais ameaça, mais pena e menos tolerância está precisamente incursa na Teoria da Tolerância Zero, segundo a qual se castigam pequenos delitos, atacando-se o mal pela raiz, considerando que a sensação de insegurança se deve mais a esses pequenos delitos. Contudo, há que ter em conta que os pequenos delitos estáo relacionados às condiçóes sociais, fazendo com que essa política de Tolerância Zero criminalize mais a pobreza.

As penas tendem a ser graves, desproporcionais ao delito e à culpabilidade e, mesmo assim, não conseguem ser eficazes.

Sua vertente positiva teria mais vantagens se fosse bem aplicada. Vende-se ao cidadão uma ideia de inseguridade e, depois, cria-se uma norma para estabilizar e tranquilizar os cidadãos. Isso nos vai aproximando do retribucionismo. 


\subsubsection{Prevenção Especial}

Em razão de a culpabilidade estar baseada na ideia de liberdade de vontade, não se questiona qual influencia teve o entorno social para quem se torna um delinquente, simplesmente diz que era livre, cometeu o crime e precisa ser reabilitado. Não será hora de nos perguntamos: Quem estamos mandando para a prisão? E por quê? Necessitam da prisão?

A crise na ideia de ressocialização é tamanha que, diante da impossibilidade de conseguir tal intento, contenta-se com as simples ideias da não dessocialização e da incapacitação. É o reconhecimento da impotência do Estado diante do homem criminoso.

A ideia da não dessocialização se desloca para dois pontos: o indíviduo que ingressa no sistema penal não deve sair pior do que entrou; e, se possível, como o sistema carcerário nada mais é do que um perpetuador de condutas ilícitas, deve-se apelar para as alternativas à prisão.

A ideia da inocuização, uma mera custódia e controle para evitar novos delitos, se faz por meio da aplicação das seguintes teorias:

a) Teoria Selective Incapacitation: enquanto o preso está na prisão, não reincide, não coloca em perigo a sociedade; assim, quanto mais tempo esteja na prisão melhor. Sem embargo, por uma razão de economia, devem-se selecionar os indivíduos que cometem a maior parte dos delitos, que tem maior probabilidade de reincidência, os que são especialmente perigosos, cabendo perguntar, nesse ponto, como se deve determinar essa maior perigosidade;

b) Teoria Three Strikes and you're out: depois do cometimento dos delitos, o terceiro se deve castigar mais gravemente porque demonstra que é incorrigível. $\mathrm{O}$ que demonstra uma afronta ao Princípio "non bis in idem".

Há uma diminuição ou quase anulação da tolerância perante um fato praticado descrito na lei como crime. Essa ideia de mais ameaça, mais pena e menos tolerância está precisamente disciplinada em outra teoria, a da Tolerância Zero, que criminaliza cada vez mais a pobreza.

\section{Conclusões}

A sociedade, na medida de suas necessidades, foi criando e definindo o comportamento de seus componentes, enquadrando-os de acordo com os valores de cada época, tendo sempre em consideração a ideia de força.

Parece claro que a ideia da justiça do Direito está intimamente ligada à legitimidade do poder, considerando assim que o poder sem direito é cego e o direito sem poder é vazio. 
Com as transformaçóes ocorridas na sociedade se faz sentir uma nova forma de ver o direito e, sobretudo, o Direito Penal. O cidadão se sente inseguro mediante um panomara de violência e cobra do Estado uma efetiva intervenção para erradicação, ou pelo menos, de um ponto de vista mais realista, para a diminuição da violência e dos conflitos sociais.

Em nosso entender, o cidadão parte da ideia que entre ter uma liberdade aparente com pouca ou nenhuma segurança - e dizemos aparente porque vivemos em uma sociedade onde os conflitos sociais colocam em perigo os bens imprescindíveis para o desenvolvimento da pessoa e não há uma confiança mútua entre os participantes de um mesmo conglomerado social - e uma maior intervenção do Estado em seu direito de liberdade em favor da uma maior segurança, o cidadão não vê outra possibilidade que optar em abrir mão de uma (grande) parcela de liberdade em favor de uma maior segurança.

No entanto, essa eficácia que o cidadão busca não pode ser encontrada em um maior endurecimento do Direito Penal, este eleito como primeiro e único meio de combate aos desvios da sociedade.

A manutenção de um Estado Constitucional e Democrático, que possui na sua Carta Maior um catálogo de direitos e garantias e, ainda, como fundamento o Princípio da Dignidade da Pessoa, requer que o direito de punir de um Estado sofra inúmeras limitaçôes. E isso, por várias razóes, dentre as quais:

a) O Estado, por ter legitimidade para intervir nos casos de ataques aos bens jurídicos protegidos, precisa usar moderadamente desse direito que lhe foi conferido para que não acabe se igualando ao criminoso, perdendo, assim, a sua legitimidade perante a sociedade e perante o próprio criminoso;

b) O Estado está delineado pelos contornos da democracia, do liberalismo, do social e do garantismo, não podendo, assim, ultrapassar a barreira criada pela Constituição quando da previsão de inúmeros direitos e garantias assegurados aos cidadãos, entre eles o direito à liberdade e à presunção de inocência;

c) O Estado somente pode intervir nos casos de ofensas aos bens jurídicos por meio de um devido procedimento, respeitando o acusado como cidadão, independentemente da acusação que lhe recai. Nesse sentido, o Estado, como órgão acusador, precisa estar na mesma posição que o acusado para que se possa realmente assegurar o princípio da igualdade processual. Além disso, como órgão julgador, o Estado nunca poderá perder de vista que, antes de possuir o adjetivo acusado, ele próprio é o substantivo, o cidadão;

d) Para a possível aplicação de uma sanção é necessário que se observem os princípios e garantias, dispostos na Lei Maior para o processo penal, entre eles, o devido processo legal, a ampla defesa e o contraditório, o direito à prova e à presunção de inocência; 
e) O Estado não deve aplicar penas indeterminadas e cruéis ou tratamentos forçados, pretendendo, assim, a ressocialização ou a reabilitação do condenado. $\mathrm{O}$ princípio da dignidade humana, mais uma vez, terá um papel importantíssimo nesse momento de individualizaçáo da resposta penal porque enseja a ideia de que se deve respeitar a personalidade e a autodeterminação de cada um;

f) Também devem ser respeitadas, quando da aplicação de uma pena, as finalidades de prevenção;

g) E, sobretudo, o agente deve ser responsabilizado pelo que fez e não pelo que é ou pelo que pensa.

Em resumo, poderíamos dizer que o direito de punir está limitado a quatro situaçôes: no funcional, devendo respeitar os limites do devido processo legal; no objetivo, vinculado à ordem jurídica como um todo; no subjetivo, porque somente pode ser exercido pelo Estado, sendo um direito indelegável; e no material, já que deve respeitar os princípios informadores.

De tudo isso, fica claro perceber que a crise que envolve o sistema punitivo se apresenta em várias dimensóes: na eficiência, na legitimação social e na ética.

\section{Referências}

ALEXY, Robert. Constitucionalismo discursivo. Tradução de Luís Afonso Heck. 3. ed. Porto Alegre: Livraria do Advogado, 2011.

ANDRADE, Manuel Costa. A dignidade penal e a carência de tutela penal, como referências de uma doutrina teológico-racional do crime. Coimbra, [s.d.].

. A nova lei dos crimes contra a economia à luz do conceito de 'Bem Jurídico'.

In: Direito Penal Económico. Coimbra: Centro de Estudos Judiciários, 1985, p. 76-85.

BARBERO SANTOS, M. Contribución al estudio de los delitos de peligro abstracto. ADPCP, p. 488 e ss., 1973.

BECCARIA, Cesare. Dos Delitos e das Penas. Tradução de Lucia Guidicini y Alessandro Berti Contessa. São Paulo: Martins Fontes, 1996.

BERGALLI, Roberto. Conflicto social y control penal. RFDUC, n. 11, 1986, p. 99-115.

BITENCOURT, Cezar. Tratado de direito penal: parte geral. 12. ed. São Paulo: Saraiva, 2012.

BONAVIDES, Paulo. Do estado liberal ao estado social. 11. ed. São Paulo: Malheiros, 2013. 
CALSAMIGLIA, Alberto. Introducción a la ciencia jurídica. Barcelona: Ariel, 1990.

COPETTI, André. Direito penal e estado democrático de direito. Porto Alegre: Livraria do Advogado, 2000.

CLÈVE, Clemerson Merlin. Para uma dogmática constitucional emancipatória. Belo Horizonte: Fórum, 2012.

DE LUCAS, Javier (coord.). Introducción a la teoria del derecho. 3. edición. Valencia: Tirant lo Blanch, 1997.

DIAS, Jorge Figueiredo. Direito Penal 2: parte geral: as consequências jurídicas do crime. Coimbra: Faculdade de Direito, 1988.

. Liberdade, culpa e direito penal. 3. ed. Coimbra: Ed. Coimbra, 1995.

FERRAJOLI, Luigi. Derechos y Garantías. Tradução de Andrés Ibáñez y Andrea Greppi. 2. ed. Madrid: Ed. Trotta, 2001.

. El derecho como sistema de garantías. In: Jueces para la Democracia. Barcelona, 1992, p. 16-17.

GARCÍA ARÁN, Mercedes. Remisiones normativas, leyes penales en blanco y estructura de la norma penal. Estudios Penales y Criminológicos, n.16, p. 65-103, 1993.

GRAY, John. Liberalismo. Tradução de María Tereza de Mucha. Madrid: Ed. Alianza, 1994.

HASSEMER, Winfried. Fundamentos del derecho penal. Barcelona: Ed. Bosch, 1984. . Por qué y con qué fin se aplican las penas? Revista de Derecho Penal y Criminología, n. 3, p. 317-331, 1999.

MANTOVANI, F. Diritto penale: parte generale. 3. ed. Padova: CEDAM, 1992, p. 236 e ss.

MIRANDA, Jorge. Teoria do estado e da constituição. 3. ed. Rio de Janeiro: Forense, 2011.

MIR PUIG, Santiago. El derecho penal en el estado social y democrático de derecho. Barcelona: Ed. Ariel, 1994.

MORAIS, José Luis Bolzan de; NASCIMENTO, Valéria Ribas do. Constitucionalismo e cidadania: por uma jurisdição constitucional democrática. Porto Alegre: Livraria do Advogado, 2010.

MORALES, Ángel Garrorena. Teoría de la constitución y sistema de fuentes. Madrid: Centro de Estudios Políticos y Constitucionales, 2011.

MUNOOZ CONDE, Francisco. El "moderno" derecho penal en el nuevo código penal: principios y tendencias. La Ley, n.3, 1996. 
; GARCÍA ARÁN, M.: Derecho penal: parte general. 5. ed. Valencia: Ed. Tirant Lo Blanch, 2002.

; HASSEMER, WINFRIED: Introducción a la criminología. Valencia: Ed. Tirant lo Blanch, 2001.

POLAINO NAVARRETE, Miguel. El bien jurídico en el derecho penal. Universidad de Sevilla, 1974.

PRITTWITZ, Cornellius. Sociedad del riesgo y Derecho Penal. In: Material del Programa de Doctorado "Problemas Actuales del Derecho Penal y de la Criminología". n. 6, 2003.

RODRÍGUEZ MONTANEES, T. Delitos de peligro, dolo e imprudencia. Madrid, 1994.

ROXIN, Claus. Acerca del desarrollo reciente de la politica criminal. CPC, n. 48, p. 795$810,1992$.

. La evolución de la política criminal, el derecho penal y el processo penal. Tradução de Carmen Gómez Rivero y María del Carmen García Cantizano. Valencia: Ed. Tirant lo Blanch, 2000.

. Sentido y Limites de la Pena Estadual. In: Problemas básicos del derecho penal. Madrid: Reus, 1976.

SILVA SÁNCHEZ, Jesus Maria. Aproximación al derecho penal contemporáneo. Barcelona: Ed. J. Ma Bosch, 1992.

. Consideraciones dogmáticas y de política legislativa sobre el fenómeno de la conducción suicida. La Ley, n. 3, p. 977 e ss., 1998.

. Legislación penal socio-económica y retroactividad de disposiciones favorables: el caso de las "leyes penales en blanco". Revista Jurídica de Cataluńa, n.1, p. 87-89, 1994.

. Nuevas tendencias politico-criminales y actividad jurisprudencial del Tribunal Supremo. Actualidade Pena, n.15/8, p. 250, 1996.

. Reflexiones sobre las bases de la politica criminal. In: Libro Homenaje al Profesor Doctor D. Tório López. Granada: Ed. Lomares, 1999. p. 209-217.

. La expansión del derecho penal: aspectos de la política criminal en las sociedades postindustriales. Madrid: Civitas, 1999.

SILVA, José Afonso da. Curso de direito constitucional positivo. 36. ed. São Paulo: Malheiros, 2013.

STRECK, Lenio Luiz; MORAIS, Jose Luis Bolzan. Comentário ao art. $1^{\circ}$, caput. In: CANOTILHO, José Joaquim Gomes et al. (coords.). Comentários à Constituiçáo do Brasil. São Paulo: Saraiva/Almedina, 2013. 
TOLEDO, Francisco de Assis. Princípios básicos de direito penal. 5. ed. São Paulo: Saraiva, 1994.

TÓRIO LÓPEZ, A. Los delitos de peligro hipotético. ADPCP, T. XLIV, 1991.

VERGARA, Francisco. Introducción a los fundamentos filosóficos del liberalismo. Versión de Javier Cid. Madrid: Ed. Alianza, 1999.

ZAFFARONI, Eugenio Raúl. Tratado de derecho penal: parte general. Buenos Aires: Ed. Ediar, 1981. V. III e IV.

ZAGREBELSKY, Gustavo. El derecho dúctil: ley, derechos y justicia. 10. ed. Madrid: Trotta, 2011. 